\title{
Biocontrole de Listeria monocytogenes por Pediococcus acidilactici em couve minimamente processada
}

\author{
Biocontrol of Listeria monocytogenes by Pediococcus acidilactici in fresh-cut kale \\ Wanessa Altimiras COSTA ${ }^{1}$, Maria Cristina Dantas VANETTI ${ }^{1 *}$, Rolf PUSCHMANN ${ }^{2}$
}

\begin{abstract}
Resumo
Este estudo avaliou um sistema de biocontrole para inibição de Listeria monocytogenes em couve minimamente processada, objetivando sua segurança durante estocagem sob refrigeração e em condições de abuso de temperatura. O potencial inibitório de bactérias láticas tolerantes ao sal e psicrotróficas contaminantes naturais da couve e Lactobacillus plantarum, Lactobacillus delbrueckii ATCC 9649 e Lactobacillus casei CCT 1465 foram avaliadas contra L. monocytogenes. O isolado de couve identificado como P. acidilactici CCA3 inibiu L. monocytogenes a 10 e $15{ }^{\circ} \mathrm{C}$ em ágar MRS e foi selecionado como possível agente de biocontrole. O número de L. monocytogenes na couve minimamente processada aumentou 3,7 e 4,7 ciclos logarítmicos a 5 e $10^{\circ} \mathrm{C}$, respectivamente, após 20 dias de armazenamento e 4,6 ciclos logarítmicos após oito dias a $15{ }^{\circ} \mathrm{C}$. Entretanto, quando $10^{8} \mathrm{UFC} . \mathrm{g}^{-1}$ de $P$. acidilactici CCA3 foram inoculados no produto processado, o crescimento de L. monocytogenes reduziu 2,3 ciclos logarítmicos sob temperatura abusiva de $15^{\circ} \mathrm{C}$. A acidez titulável e as características sensoriais da couve não foram alteradas pela presença de CCA3 ao longo do período de vida útil. Estes resultados sugerem o potencial de aplicação dos bioconservantes na couve minimamente processada, que necessitam estar associados à refrigeração e sanitização para garantir segurança. Palavras-chave: biopreservação; segurança alimentar; Listeria monocytogenes; bactérias láticas.
\end{abstract}

\begin{abstract}
This study evaluated a biological control system for the inhibition of Listeria monocytogenes in minimally processed kale focusing on its freshness under refrigeration and extreme temperatures. The inhibitory potential of salt and cold tolerant lactic bacteria from natural microflora of kale, Lactobacillus delbrueckii ATCC 9649, Lactobacillus plantarum, and Lactobacillus casei CCT 1465 strains were evaluated against L. monocytogenes. Pediococcus acidilactici CCA3 isolated from kale exhibited a large inhibition zone of L. monocytogenes at 10 and $15{ }^{\circ} \mathrm{C}$ in MRS agar and was selected as a possible biological control bacterium. The population of L. monocytogenes inoculated in minimally processed kale increased 3.7 and 4.7 logarithmic cycles at 5 and $10{ }^{\circ} \mathrm{C}$, respectively, after 20 days of storage and 4.6 logarithmic cycles at $15{ }^{\circ} \mathrm{C}$ after eight days. However, when $10^{8} \mathrm{CFU} \cdot \mathrm{g}^{-1}$ of $P$. acidilactici CCA3 was inoculated into processed product a reduction of L. monocytogenes of 2.3 logarithmic cycles under extreme temperature conditions $\left(15^{\circ} \mathrm{C}\right)$ occurred. P. acidilactici CCA3 did not alter the titratable acidity or the kale sensorial characteristics during the shelf life period. These results suggest the potential application of biopreservatives on minimally processed kale that need to be associated with refrigeration and sanitation to assure safety.

Keywords: biopreservative; safety food; Listeria monocytogenes; lactic bacteria.
\end{abstract}

\section{Introdução}

No Brasil, a produção agrícola se estende a praticamente todos os itens essenciais à alimentação. No entanto, há grandes perdas quantitativas, qualitativas e nutricionais, em razão de práticas inadequadas no manuseio após a colheita, no transporte e no armazenamento dos produtos agrícolas. A técnica de processamento mínimo de hortaliças objetiva reduzir os desperdícios desses produtos, favorecendo a economia de alimentos no País e contribuindo também para melhorar a qualidade e estender a vida de prateleira deles. A principal medida de conservação de produtos minimamente processados é a refrigeração (FRANCIS; O'BEIRNE, 2001; MARTH, 1998), pois a temperatura é o fator mais importante que afeta as características gerais de qualidade do produto tais como aparência, textura e conteúdo em vitaminas (WATADA, 1999).
Temperaturas baixas durante o transporte, armazenamento e distribuição dos produtos minimamente processados diminuem a velocidade de senescência e outros processos metabólicos, reduzem a deterioração e podem minimizar os efeitos do etileno (BRECHT, 1995). Entretanto, a manutenção da temperatura baixa durante a distribuição, transporte e comercialização ou antes de serem consumidas é o principal problema associado a frutas e hortaliças minimamente processadas (WILEY, 1994). O abuso de temperatura pode dar condição e tempo para a sobrevivência e o crescimento de patógenos psicrotróficos (SZABO; SCURRAHAND; BURROWS, 2000).

Associada às baixas temperaturas, a modificação da atmosfera é outra barreira que atua no controle da deterioração

Recebido para publicação em 17/12/2007

Aceito para publicação em 3/1/2009 (003108)

${ }^{1}$ Departamento de Microbiologia, Universidade Federal de Viçosa - UFV, Viçosa - MG, Brasil, E-mail: mvanetti@ufv.br

${ }^{2}$ Departamento de Biologia Vegetal, Universidade Federal de Viçosa - UFV, CEP 36570-000, Viçosa - MG, Brasil

${ }^{*}$ A quem a correspondência deve ser enviada 
do produto, mas pode proporcionar oportunidade para o crescimento de espécies psicrotróficas anaeróbias facultativas (FRANCIS; O'BEIRNE, 2001; THOMAS; O'BEIRNE, 2000). Considerando que a maioria desses alimentos é consumida sem nenhum tratamento térmico, uma das principais preocupações é com relação a bactérias patogênicas capazes de crescerem em temperatura de refrigeração (FARBER, 1991; SCHUENZEL; HARRISON, 2002; SZABO; SCURRAHAND; BURROWS, 2000). Dentre os patógenos que podem ser encontrados em produtos vegetais frescos destacam-se Aeromonas hydrophila, Clostridium botulinum, Listeria monocytogenes, Yersinia enterocolitica, Salmonella spp., Escherichia coli O157:H7 e Campylobacter jejuni (DHOKANE et al., 2006; SCHUENZEL; HARRISON, 2002; SZABO; SCURRAHAND; BURROWS; 2000).

L. monocytogenes é uma bactéria patogênica que pode causar doenças sistêmicas em humanos, tais como septicemia, meningite, infecção no sistema nervoso central e até mesmo a morte (OKTEM; BAYRAM; CEYLAN, 2006). A taxa de mortalidade é alta em indivíduos susceptíveis, como mulheres grávidas, recém-nascidos, idosos e pessoas imunodeprimidas e pode alcançar de 20 a $30 \%$ em alguns casos epidêmicos (GANDHI; CHIKINDAS, 2007; NORRUNG, 2000; OKTEM, 2006).

A prevalência de L. monocytogenes em alimentos minimamente processados e a alta taxa de mortalidade por listeriose fizeram dessa bactéria um problema importante a ser considerado quando da avaliação dos riscos microbiológicos em alimentos prontos para consumo (NORRUNG; ANDERSEN; SCHLUNDT, 1999). L. monocytogenes sobrevive e/ou cresce em produtos minimamente processados, mantidos sob refrigeração (CARLIN; NGUYEN-THE; SILVA, 1995; CATELLANI; GIACCONE; NOVELLI, 2006; FARBER et al., 1998; NORRUNG, 2000; SINIGAGLIA, 2006) e a incidência desse patógeno em hortaliças minimamente processadas varia, normalmente, de 0 a 19\% (BEAULIEU et al., 1997; CARLIN; NGUYEN-THE; SILVA, 1995; NGUYEN-THE; CARLIN, 1994; ODUMERU et al., 1997; SORIANO et al., 2001). O potencial para sobrevivência e crescimento de Listeria em hortaliças minimamente processadas depende do tipo de hortaliça, idade do produto, concentração do patógeno, procedimento adotado no processamento, temperatura e atmosfera de armazenamento (CARLIN; NGUYEN-THE; SILVA, 1995; FRANCIS; O'BEIRNE, 2001; NGUYEN-THE; CARLIN, 1994; THOMAS; O’BEIRNE, 2000).

$\mathrm{O}$ aumento da segurança microbiológica em hortaliças minimamente processadas pode ser alcançado com a utilização de barreiras adicionais, como por exemplo, a competição microbiana, a adição de bacteriocinas e outros compostos GRAS (Geralmente Reconhecidos como Seguros) (SCHILLINGER et al., 2001; SCHUENZEL; HARRISON, 2002; SOOMRO; MASUD; ANWAAR, 2002). O uso de bactérias láticas como competidoras da microbiota deterioradora e patogênica é amplamente estudado em produtos cárneos e láticos, mas só recentemente a sua aplicação em frutas e hortaliças minimamente processadas tem sido considerada (VESCOVO et al., 1995; VESCOVO et al., 1996). Por apresentarem atividades antagonista e competitiva, bactérias do ácido lático podem inibir ou mesmo eliminar patógenos em alimentos minimamente processados e melhorar com isso a vida útil e a segurança desses alimentos (SCHUENZEL; HARRISON, 2002).

Entre as hortaliças de importância econômica para o Brasil, a couve destaca-se como uma das mais comercializadas e consumidas. Aspectos do processamento mínimo da couve foram considerados em outros estudos (BITTENCOURT 2000; CARNELOSSI, 2000; DANTAS 2001; TELES 2000) e, com propósitos de complementar essas informações, o presente estudo se propôs a avaliar o potencial de crescimento de L. monocytogenes em couve minimamente processada e o potencial inibidor de bactérias láticas sobre esse patógeno.

\section{Material e métodos}

\subsection{Seleção da bactéria lática a ser inoculada na couve minimamente processada}

Com o objetivo de selecionar bactérias láticas que apresentassem atividade inibitória sobre L. monocytogenes em temperaturas de refrigeração, foi feito o isolamento de bactérias produtoras de ácido a partir de couve minimamente processada adicionada de 2,5\% de cloreto de sódio e estocada por 6 dias a 7 e $21^{\circ} \mathrm{C}$. O isolamento foi feito em superfície de ágar Man, Rogosa e Sharpe - MRS (Oxoid, Basingstore, Inglaterra) acrescido de 0,04 g.L. ${ }^{-1}$ de púrpura de bromocresol e 5,0 g.L $\mathrm{L}^{-1}$ de carbonato de cálcio, após incubação a $30^{\circ} \mathrm{C}$ por 48 horas, sob microaerofilia. Foram selecionadas de três a cinco colônias produtoras de ácido e que apresentaram aspectos morfológicos diferentes. A identificação das bactérias isoladas foi realizada por comparação dos perfis de ésteres metílicos de ácidos graxos (FAME) com os de uma biblioteca de referência do sistema Sherlock da Microbial Identification System ${ }^{\bullet}$ (MIDI, Newark, DE, EUA) (TSBA versão 5,0).

A atividade antilistérica foi avaliada nas culturas isoladas e em culturas de Lactobacillus delbrueckii subsp. delbrueckii ATCC 9649 e Lb. plantarum, obtidas do laboratório de Microbiologia Industrial (Bioagro-UFV) e Lactobacillus casei CCT 1465, obtida da Fundação André Tosello. Todas as culturas usadas neste experimento foram submetidas aos testes de coloração de Gram, catalase e confirmação da produção de ácido em ágar MRS acrescido de 0,04 g.L.-1 de púrpura de bromocresol e 5,0 g.L. $\mathrm{L}^{-1} \mathrm{de}$ carbonato de cálcio. As culturas puras foram estocadas a $-80^{\circ} \mathrm{C}$ em caldo MRS acrescido de 20\% (v/v) de glicerol.

Um dos critérios utilizados para a seleção da cultura lática a ser inoculada na couve minimamente processada foi a capacidade de crescimento sob refrigeração. As culturas láticas usadas neste estudo foram ativadas em caldo MRS a $35^{\circ} \mathrm{C}$ por 18 horas, transferidas para caldo MRS e incubadas a 5, 10 e $15^{\circ} \mathrm{C}\left( \pm 1^{\circ} \mathrm{C}\right) . \mathrm{O}$ crescimento foi acompanhado por medida da densidade óptica (DO) em espectrofotômetro Spectronic $20 \mathrm{D}$ (Milton Roy Company, NY, EUA). O segundo critério para a seleção da cultura lática foi quanto à capacidade de inibição de L. monocytogenes quando avaliadas pela técnica de difusão em meio sólido (36). Utilizou-se o ágar MRS com 0,2 e 20\% (p/v) 
de glicose, para verificar se a inibição de L. monocytogenes pelas bactérias láticas era devida, exclusivamente, à produção de ácido.

\subsection{Estirpes de L. monocytogenes utilizadas}

Estirpes de L. monocytogenes Scott A, ATCC 7644, IP2-40 e 764/93 foram obtidas do estoque de culturas do laboratório de Microbiologia de Alimentos da Universidade Federal de Viçosa (Viçosa, MG), ativadas em tubos com $5 \mathrm{~mL}$ de caldo TSB acrescentado de $0,6 \%$ de extrato de levedura a $35 \pm 2{ }^{\circ} \mathrm{C}$ por 17 horas.

\subsection{Inoculação de L. monocytogenes e bactéria lática na couve minimamente processada}

Após ativação, as estirpes de L. monocytogenes foram misturadas, na mesma proporção, em um único tubo. A suspensão de células foi padronizada em D.O. igual a 0,27 utilizando-se o comprimento de onda de $600 \mathrm{~nm}$ em espectrofotômetro Spectronic $20 \mathrm{D}$ e que corresponde a $10^{8}$ UFC. $\mathrm{mL}^{-1}$ de L. monocytogenes.

A estirpe de bactéria lática selecionada foi ativada em $5 \mathrm{~mL}$ de caldo MRS, a $35 \pm 2{ }^{\circ} \mathrm{C}$ por 17 horas, quando atingiu a população de, aproximadamente, $10^{9}$ UFC. $\mathrm{mL}^{-1}$. Células de L. monocytogenes e da bactéria lática foram coletadas por centrifugação a $2000 \mathrm{~g}$ por 15 minutos em centrífuga Sorvall RC5C e lavadas em solução salina $0,85 \%$ por duas vezes. Diluições sucessivas foram feitas, para inoculação de, aproximadamente, $10^{5}$ UFC de Listeria e $10^{8}$ UFC da cultura lática por grama de couve.

Após a inoculação das culturas, as embalagens de couve minimamente processadas foram seladas e armazenadas em estufas a 5,10 e $15{ }^{\circ} \mathrm{C}\left( \pm 1{ }^{\circ} \mathrm{C}\right)$ e, periodicamente, amostras foram retiradas para se proceder às análises microbiológicas e de acidez titulável.

\subsection{Determinação do crescimento de L. monocytogenes em couve minimamente processada}

O crescimento de L. monocytogenes em couve minimamente processada foi acompanhado no produto estocado a 5, $10 \mathrm{e}$ $15{ }^{\circ} \mathrm{C}$, na presença ou não da bactéria lática selecionada. $\mathrm{O}$ processamento mínimo consistiu das etapas de seleção, prélavagem, sanitização, fatiamento, enxaguagem, centrifugação, pesagem, embalagem e armazenamento, como determinado por Bittencourt (2000). Quantidades de $50 \mathrm{~g}$ de couve minimamente processada foram acondicionadas em embalagens de multicamada de poliolefina $21 \mu \mathrm{m}$, de $18 \times 11,25 \mathrm{~cm}$ e com a modificação passiva da atmosfera (CARNELOSSI, 2000; TELES, 2000).

\subsection{Análises microbiológicas}

Porções de $25 \mathrm{~g}$ de couve foram pesadas assepticamente e homogeneizadas com $225 \mathrm{~mL}$ de água peptonada $0,1 \%$ (Merck, Darmstadt, Alemanha) em Stomacher (Lab-Blender 400, Seward Medical, BA 7021, Inglaterra). A contagem de L. monocytogenes foi feita em ágar seletivo Oxford (Merck, Darmstadt, Alemanha) com a adição de suplemento seletivo e a presença de colônias típicas foi avaliada após a incubação a $35 \pm 2{ }^{\circ} \mathrm{C}$ por 48 horas. Colônias com morfologias características e circundadas por halo escuro resultante da hidrólise da esculina, no ágar Oxford, foram consideradas típicas de Listeria. Quatro colônias típicas, por diluição, foram selecionadas para a confirmação do gênero Listeria por meio de reação da catalase e teste de motilidade em ágar semissólido (Difco, Detroit, EUA) com incubação a $23^{\circ} \mathrm{C}$ por, aproximadamente, 72 horas. Para a confirmação da espécie $L$. monocytogenes, foi realizado o teste $\beta$-hemólise em placas contendo ágar Sangue (Merck, Darmstadt, Alemanha), enriquecido com sangue de carneiro.

A microbiota contaminante da couve minimamente processada foi avaliada pela contagem padrão de psicrotróficos aeróbios em ágar Padrão para Contagem - PCA (Merck), após a incubação a $7 \pm 1^{\circ} \mathrm{C}$, por 10 dias. A determinação de bactérias produtoras de ácido foi feita em ágar MRS, com a adição de 0,04 g. $\mathrm{L}^{-1}$ de púrpura de bromocresol e 5,0 g. $\mathrm{L}^{-1}$ de carbonato de cálcio, após incubação a $35 \pm 2{ }^{\circ} \mathrm{C}$, por 48 horas, em jarras Gas-Pack, sob microaerofilia. Foram consideradas bactérias láticas aquelas cujas colônias apresentaram halo amarelo, caracterizando a produção de ácido e que foram catalase negativas (HALL; LEDENBACH; FLOWERS, 2001).

\subsection{Determinação da acidez titulável}

A acidez titulável da couve foi determinada conforme Case, Bradley e Williams (1985), em homogenato preparado em água destilada.

\subsection{Análise estatística}

O estudo da velocidade específica de crescimento $(\mu)$ de $L$. monocytogenes na couve minimamente processada foi conduzido segundo o esquema de parcela subdividida tendo nas parcelas dois tratamentos (couve minimamente processada com L. monocytogenes e couve minimamente processada com L. monocytogenes e Pediococcus acidilactici CCA3) e na subparcela, os períodos de estocagem a 5 e $10{ }^{\circ} \mathrm{C}(0,5,10$, 15 e 20 dias) e a $15^{\circ} \mathrm{C}(0,2,4,6$ e 8 dias $)$, no delineamento inteiramente casualizado, com três repetições. Os dados foram submetidos à análise de variância e de regressão. Para o fator qualitativo, as médias foram comparadas pelo teste de Tukey a $5 \%$ de probabilidade. Para o fator quantitativo, os modelos foram escolhidos baseados na significância dos coeficientes de regressão, utilizando-se o teste $t$ de Student, adotando-se o nível de $5 \%$ de probabilidade, no coeficiente de determinação e no fenômeno biológico. O experimento que avaliou a concentração de ácido lático na couve minimamente processada foi conduzido segundo o delineamento inteiramente casualizado com três temperaturas $\left(5,10\right.$ e $\left.15^{\circ} \mathrm{C}\right)$, dois tratamentos, com e sem o isolado CCA3, com três repetições. Os dados foram submetidos à análise de variância e as médias comparadas pelo teste de Tukey a $5 \%$ de probabilidade. 


\section{Resultados e discussão}

\subsection{Identificação e seleção da bactéria lática}

As bactérias láticas isoladas da couve foram identificadas pelo sistema MIDI e denominadas Pediococcus acidilactici CCA3, Pediococcus damnosus CCA7 e Lactobacillus parabuchneri BNCCR5. Maior velocidade de crescimento nas temperaturas de refrigeração foi alcançada pelo isolado CCA3 de P. acidilactici (Figura 1), fator importante a ser considerado na seleção da cultura para uso como bioconservante no produto minimamente processado. Além de crescimento rápido, as taxas de produção de compostos antimicrobianos e a sensibilidade relativa do patógeno a estes metabólitos também afetam o resultado competitivo entre as culturas a serem usadas como bioconservantes (BREIDT; FLEMING, 1997; SOOMRO; MASUD; ANWAAR, 2002).

O isolado de couve $P$. acidilactici CCA3 apresentou atividade antilistérica a 10 e $15^{\circ} \mathrm{C}$, enquanto os isolados $P$. damnosus CCA7 e Lb. parabuchneri BNCCR5 e as culturas Lb. delbrueckii subsp. delbrueckii e Lb. casei inibiram o crescimento de L. monocytogenes quando incubados somente a $15^{\circ} \mathrm{C}$ e em ágar MRS contendo $20 \%$ de glicose, mas não na presença de $0,2 \%$ de glicose. Este resultado sugere que a inibição de L. monocytogenes foi, provavelmente, devido à produção de ácido pelas bactérias láticas. Wilson et al. (2005) verificaram que a inibição de $L$. monocytogenes por $L b$. plantarum SK1 em meio MRS foi também em razão da produção de ácido lático e o efeito inibidor dessa cultura foi mantido em rabanetes armazenados a $5{ }^{\circ} \mathrm{C}$. No entanto, a inibição de patógenos por bactérias láticas pode ser também pela produção de bacteriocinas (PONCE et al., 2007; SPELHAUG; HARLANDER, 1989; VESCOVO et al., 1996).

\subsection{Crescimento de L. monocytogenes em couve minimamente processada}

Durante o período de armazenamento da couve minimamente processada inoculada com L. monocytogenes e estocada a 5 e $10{ }^{\circ} \mathrm{C}$, houve um aumento expressivo da população do patógeno que alcançou, após o décimo quinto dia, $10^{6}$ e $10^{8}$ UFC.g $^{-1}$, respectivamente (Figura 2a, b). No armazenamento da couve a $15^{\circ} \mathrm{C}$ a população de $10^{8} \mathrm{UFC} \cdot \mathrm{g}^{-1}$ foi alcançada no sexto dia de estocagem (Figura 2c). Esse crescimento observado corresponde aos aumentos, respectivamente, de 3,7 e 4,7 a 5 e $10^{\circ} \mathrm{C}$ após 20 dias de estocagem (Figura $2 \mathrm{a}, \mathrm{b}$ ) e a 4,6 ciclos logarítmicos após oito dias a $15^{\circ} \mathrm{C}$, condição esta que simula abuso na temperatura de estocagem (Figura 2c). Estes
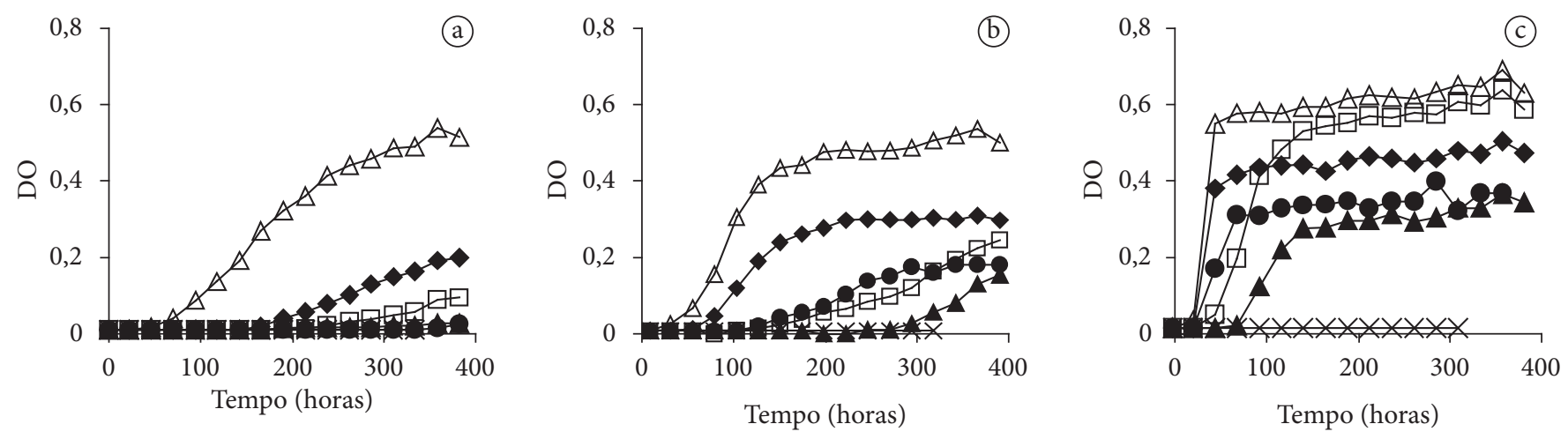

Figura 1. Curva de crescimento das bactérias láticas Lb. casei ( $\square)$, Lb. delbrueckii $(\boldsymbol{\Delta})$, Lb. plantarum $(\times)$, Lb. parabuchneri BNCCR5 ( $\bullet)$, P. damnosus $\mathrm{CCA} 7(\bullet)$ e $P$. acidilactici CCA3 $(\Delta)$ em caldo MRS, incubadas nas temperaturas de a) 5 ; b) 10 ; e c) $15^{\circ} \mathrm{C}$.
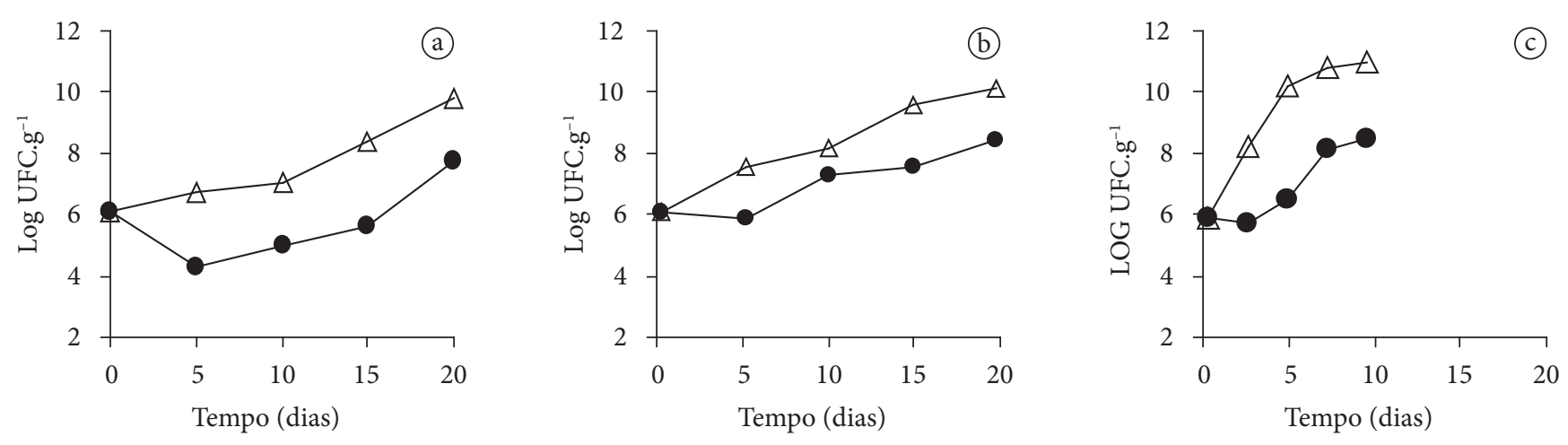

Figura 2. Logaritmo do número de Unidades Formadoras de Colônias (UFC. ( $^{-1}$ ) de L. monocytogenes em couve minimamente processada estocada a 5 (A) e 10 (B) por 20 dias e $15^{\circ} \mathrm{C}(\mathrm{C})$ por 8 dias. Produto inoculado com L. monocytogenes $(\Delta)$ e produto inoculado com L. monocytogenes e $P$. acidilactici (CCA3) (•). 
resultados reforçam o risco do crescimento desse patógeno psicrotrófico em alimentos minimamente processados e mantidos por períodos prolongados a temperaturas baixas, ou durante períodos de tempo menor, mas em temperaturas abusivas.

O crescimento de L. monocytogenes também já foi constatado em produtos minimamente processados, estocados sob refrigeração como em alface manteiga e endívia (NGUYEN-THE; CARLIN, 1994), em saladas diversas (FARBER, 1998), em aspargos (RODRÍGUEZ et al., 2000), em alcachofras (SANZ; GIMÉNEZ; OLARTE, 2003) e em coco (SINIGAGLIA et al., 2006).

L. monocytogenes inoculada em couve minimamente processada cresceu simultaneamente com o isolado $P$. acidilactici CCA3 nas condições de estocagem do produto (Figura 2a, b, c). Pelos valores de velocidade específica de crescimento $(\mu)$ de L. monocytogenes no produto inoculado com o isolado $P$. acidilactici CCA3, pode-se evidenciar uma atividade inibitória significativa $(\mathrm{p}<0,05)$ da cultura lática na temperatura de $15^{\circ} \mathrm{C}$ (Tabela 1). Nesta temperatura, a presença de CCA3 resultou em 2,3 ciclos logarítmicos a menos no crescimento de L. monocytogenes (Figura 2c).

Nessa condição, características sensoriais do produto tais como aparência e odor foram mantidas até o quarto dia de estocagem. Neste período houve um controle maior no crescimento de L. monocytogenes comparado com o mesmo período em produtos não inoculados com a bactéria lática. Este resultado permite sugerir que, em condições de abuso de temperatura, a presença de uma cultura lática pode se constituir em uma barreira adicional para o crescimento de L. monocytogenes e, provavelmente, outras bactérias indesejáveis.

Resultados similares foram obtidos por Bennik et al. (1999) que avaliaram o potencial de duas estirpes de Pediococcus parvulus e uma estirpe de Enterococcus mundtii, ambas bacteriocinogênicas, isoladas de hortaliças minimamente processadas, em controlar o crescimento de L. monocytogenes in vitro e em brotos de feijão frescos. Esses autores verificaram que as estirpes de $P$. parvulus não apresentaram atividade inibitória, in vitro, quando incubadas a 4 ou $8{ }^{\circ} \mathrm{C}$, mas essa atividade foi evidenciada quando armazenadas a 15 e $30^{\circ} \mathrm{C}$, sugerindo que essas culturas podem ser utilizadas como biocontrole em produtos que são processados ou estocados em temperaturas elevadas. Esses autores ainda evidenciaram que E. mundtii foi capaz de controlar o crescimento de

Tabela 1. Média da velocidade específica de crescimento $(\mu)$ de L. monocytogenes na couve minimamente processada, mantida a 5, 10 e $15^{\circ} \mathrm{C}$ durante o período de armazenamento.

\begin{tabular}{lccc}
\hline \multicolumn{1}{c}{ Tratamentos } & \multicolumn{3}{c}{$\mu$ de L. monocytogenes } \\
\cline { 2 - 4 } & $5^{\circ} \mathrm{C}$ & $10^{\circ} \mathrm{C}$ & $15^{\circ} \mathrm{C}$ \\
\hline L. monocytogenes & $0,2367^{\mathrm{a}}$ & $0,2633^{\mathrm{a}}$ & $0,8767^{\mathrm{a}}$ \\
L. monocytogenes e P. acidilactici CCA3 & $0,2267^{\mathrm{a}}$ & $0,2067^{\mathrm{a}}$ & $0,6833^{\mathrm{b}}$ \\
\hline
\end{tabular}

Médias seguidas de mesma letra verticalmente, não diferem entre si pelo teste de Tukey a $5 \%$ de probabilidade.
L. monocytogenes apenas em ágar contendo brotos de feijão armazenados por 5 dias a $8^{\circ} \mathrm{C}$, mas não no produto armazenado sob atmosfera modificada na mesma condição de temperatura. Resultados observados com $P$. acidilactici JBL 1095 também demonstraram que bacteriocina não foi produzida a $4{ }^{\circ} \mathrm{C} \mathrm{em}$ salsichas formuladas com carne bovina e embaladas a vácuo, enquanto a $25^{\circ} \mathrm{C}$ constatou-se redução de 2,7 ciclos logarítmicos no número de células de L. monocytogenes (DEGNAN; YOUSEF; LUCHANSKY, 1992).

Bactérias do ácido lático isoladas de hortaliças frescas inativaram patógenos como A. hydrophila, Salmonella typhimurium e Staphylococcus aureus inoculados em saladas mistas minimamente processadas em até seis dias de armazenamento a $8^{\circ} \mathrm{C}$, enquanto a concentração inicial de L. monocytogenes inoculada no produto permaneceu inalterada durante o período de armazenamento (VESCOVO et al., 1996). Quando bactérias do ácido lático e L. monocytogenes geneticamente marcadas foram inoculadas em suco e conserva de pepino, não foi observado o crescimento desse patógeno, inibição essa atribuída, principalmente, a bactérias láticas naturalmente encontradas no produto (BREIDT; FLEMING, 1997). Os resultados sugerem que contaminantes com potencial antilistérico isolados de hortaliças podem ser usados com bioconservantes promovendo o aumento da segurança dos produtos minimamente processados.

\subsection{Características microbiológicas, sensoriais e químicas da couve minimamente processada}

A inoculação de aproximadamente $10^{8} \mathrm{UFC}^{-g^{-1}}$ do isolado $P$. acidilactici CCA3 na couve minimamente processada não afetou a aparência e odor característicos do produto. As amostras de couve inoculadas ou não com o isolado $P$. acidilactici CCA3 e armazenadas a $5{ }^{\circ} \mathrm{C}$ apresentaram características aceitáveis por até 15 dias, enquanto essas características foram observadas nas amostras de couve, estocadas a 10 e $15^{\circ} \mathrm{C}$, por até $10 \mathrm{e}$ 4 dias, respectivamente. Estes resultados se assemelham aos obtidos por Bittencourt (2000) em teste de aceitação de couve minimamente processada com grupos de 90 provadores não treinados, quando foi estimada uma vida útil de até 18 dias para o produto mantido a $5^{\circ} \mathrm{C}$. Nesse mesmo estudo, o produto estocado a $10^{\circ} \mathrm{C}$ foi aceito quanto à aparência até o décimo dia, no entanto o aroma foi suficiente para promover sua rejeição no oitavo dia de armazenamento.

Durante o período de armazenamento da couve inoculada com o isolado $P$. acidilactici CCA3, não se observou aumento expressivo na população de bactérias láticas. No entanto, nas amostras controle, houve um aumento na população dessas bactérias de 0,92 a 2,74 ciclos logarítmicos a 5 e $10^{\circ} \mathrm{C}$, respectivamente, após 20 dias de estocagem e um aumento de 3,63 ciclos logarítmicos a $15^{\circ} \mathrm{C}$, após 8 dias de estocagem (Figura 3).

Em hortaliças mistas embaladas, Manvell e Ackland (1986) registraram o aumento da população de bactérias láticas com o aumento da temperatura de armazenamento. Em couve minimamente processada, o aumento na população de bactérias láticas durante o período de vida útil foi de 2,4 ciclos 


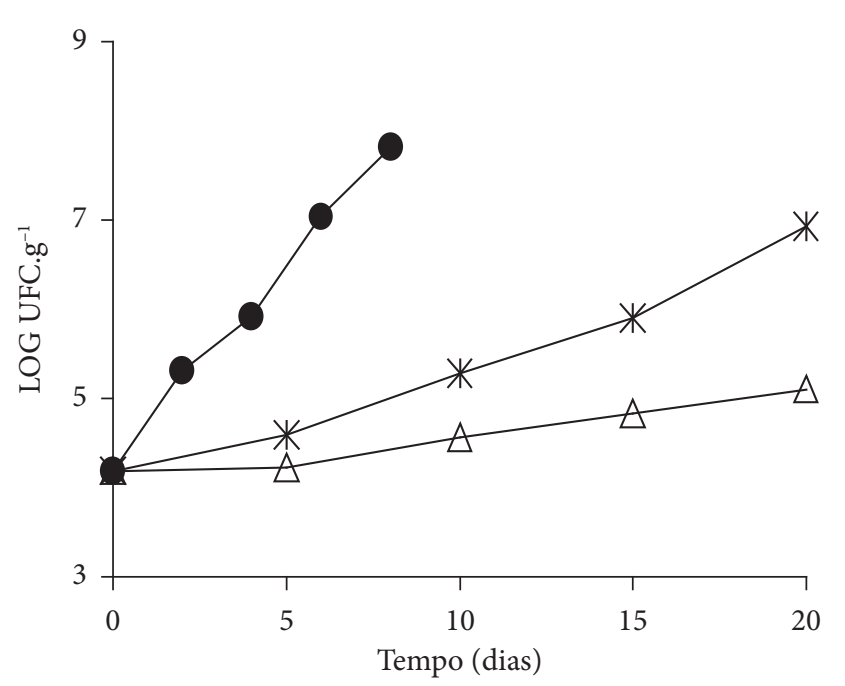

Figura 3. Logaritmo do número de Unidades Formadoras de Colônias (UFC. $\mathrm{g}^{-1}$ ) de bactérias láticas em couve minimamente processada estocada a $5(\Delta), 10\left(^{*}\right)$ e $15^{\circ} \mathrm{C}(\bullet)$ por 20 dias.

logarítmicos a $1^{\circ} \mathrm{C}, 4$ ciclos a $5^{\circ} \mathrm{C}$ e 6 ciclos logarítmicos a $10^{\circ} \mathrm{C}$ (BITTENCOURT, 2000).

A população de psicrotróficos aeróbios aumentou proporcionalmente com o aumento da temperatura (Figura 4). Bactérias psicrotróficas são agentes importantes de deterioração de hortaliças minimamente processadas e tem-se constatado que o crescimento dessa microbiota varia com o tipo de produto. Aumentos de três ciclos logarítmicos na população de psicrotróficos em couve minimamente processada mantida a $5{ }^{\circ} \mathrm{C}$ foram constatados por Bittencourt (2000). Segundo esse autor, a microbiota psicrotrófica predominou em todos os tempos de amostragem do produto mantido a $1,5 \mathrm{e} 10^{\circ} \mathrm{C}$ e foi constituída principalmente por espécies de Pseudomonas. Em alface minimamente processada estocada a $4{ }^{\circ} \mathrm{C}$ por 12 dias sob atmosfera controlada com diferentes composições gasosas, o aumento na população de microrganismos psicrotróficos foi também de três ciclos logarítmicos (BARRIGA et al., 1991).

Em amostras de repolho minimamente processado estocadas a 1 e $5^{\circ} \mathrm{C}$ por 20 dias, não foi observada variação no crescimento de psicrotróficos, mas a $12{ }^{\circ} \mathrm{C}$ essa população aumentou em aproximadamente três ciclos logarítmicos em cinco dias de armazenamento (FANTUZZI; PUSCHMANN; VANETTI, 2004).

Não houve diferença significativa $(p>0,05)$ quanto à porcentagem de ácido lático nas amostras de couve minimamente processada inoculada ou não com a cultura de P. acidilactici CCA3 durante o período de armazenamento a 5, 10 e $15^{\circ} \mathrm{C}$ (Figura 5).

A concentração de ácido lático na couve minimamente processada foi semelhante nas amostras inoculadas e não inoculadas com CCA3 nas temperaturas de 5 e $10^{\circ} \mathrm{C}$. Quando o produto foi mantido a $15{ }^{\circ} \mathrm{C}$, maior acidez titulável foi observada nas amostras inoculadas com a cultura de CCA3, comparado com o mantido a 5 e $10{ }^{\circ} \mathrm{C}$, durante os 10 dias

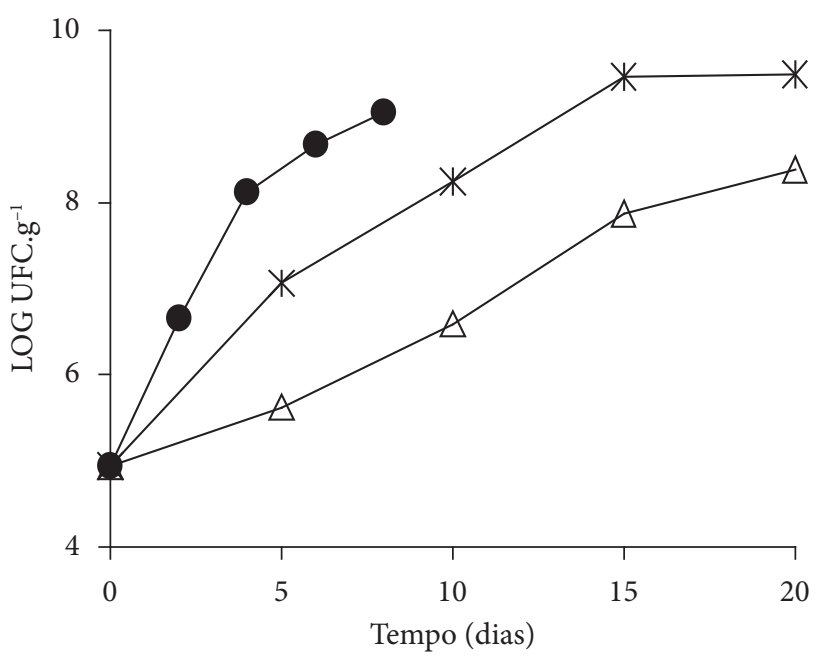

Figura 4. Logaritmo do número de Unidades Formadoras de Colônias $\left(\mathrm{UFC} \mathrm{g}^{-1}\right)$ de psicrotróficos aeróbios em função do tempo (dias) em couve minimamente processada estocada a $5(\Delta), 10\left(^{*}\right)$ e $15^{\circ} \mathrm{C}(\bullet)$.

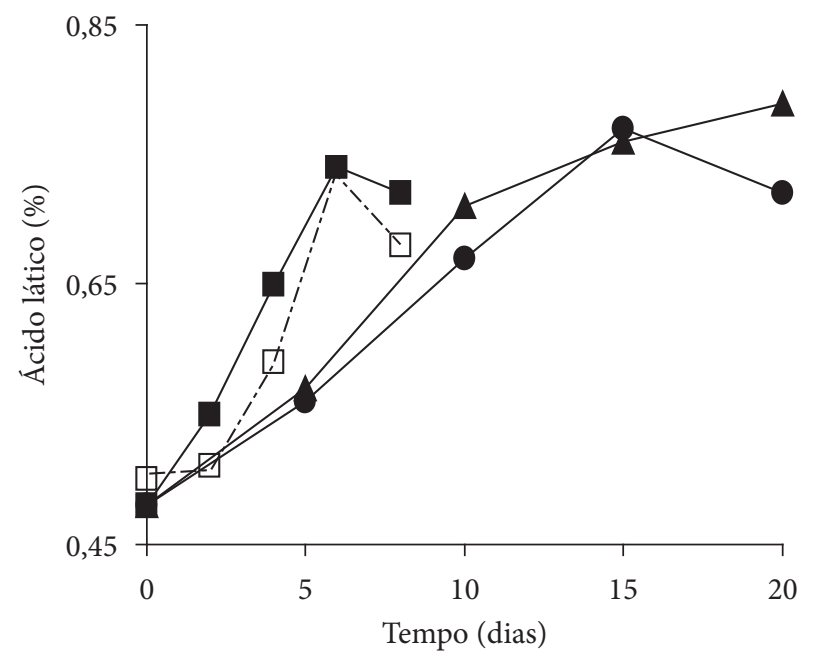

Figura 5. Concentração (\%) de ácido lático em amostras de couve minimamente processadas inoculadas com L. monocytogenes e P. acidilactici CCA3 estocadas a $5{ }^{\circ} \mathrm{C}(\bullet)$ e $10{ }^{\circ} \mathrm{C}(\boldsymbol{\Delta})$ por 20 dias e $15^{\circ} \mathrm{C}(\bullet)$ por 8 dias e de amostras controle estocadas a $15^{\circ} \mathrm{C}(\square)$ por 8 dias.

iniciais de armazenamento (Figura 5). Estes resultados foram similares aos de Manvell e Ackland (1986) que detectaram maior concentração de ácido lático em hortaliças mistas armazenadas sob condições de abuso de temperatura do que sob temperatura de refrigeração de $7^{\circ} \mathrm{C}$. Pode-se sugerir que o ácido lático tenha promovido a inibição de L. monocytogenes a $15^{\circ} \mathrm{C}$, embora deva ser considerado que $P$. acidilactici é capaz de produzir bacteriocina (BISWAS et al., 1991) e seu potencial bioconservante precisa ser mais bem avaliado. $\mathrm{O}$ uso de mais um fator de inibição de patógenos e microrganismos deterioradores deve estar associada à aplicação de boas práticas de fabricação 
para que a segurança de alimentos minimamente processados seja alcançada.

\section{Conclusões}

O potencial de utilização de bioconservante para inibição de patógenos em alimentos minimamente processados foi constatado, indicando que podem se constituir em mais uma barreira para garantir a segurança desses alimentos. Entretanto, torna-se necessário avaliar outras bactérias láticas para esta finalidade.

\section{Referências bibliográficas}

BARRIGA, M. I. et al. Microbial changes in shredded iceberg lettuce stored under controlled atmospheres. Journal of Food Science, v. 56, n. 6, p. 1586-1599, 1991.

BEAULIEU, J. C. et al. Fresh-cut kale: quality assessment of portuguese store-supplied product for development of a MAP system. CA'97. Proceedings of Postharvest Horticulture Series, v. 5, n. 19, p. 145-151, 1997.

BENNIK, M. H. et al. Biopreservation in modified atmosphere stored mungbean sprouts: the use of vegetable-associated bacteriocinogenic lactic acid bacteria to control the growth of Listeria monocytogenes. Letters in Applied Microbiology, v. 28, n. 3, p. 226-232, 1999.

BISWAS, S. R. et al. Influence of growth conditions on the production of a bacteriocin, pediocin $\mathrm{AcH}$, by Pediococcus acidilactici $\mathrm{H}$. Applied and Environmental Microbiology, v. 57, n. 4, p. 1265-1267, 1991.

BITTENCOURT, M. T. Atividade microbiana em couve (Brassica oleraceae cv. acephala) minimamente processada. Viçosa, 2000. 76 p. Dissertação, (Mestrado em Microbiologia Agrícola) Universidade Federal de Viçosa (UFV).

BRECHT, J. K. Physiology of lightly processed fruits and vegetables. HortScience, v. 30, n. 1, p. 18-21, 1995.

BREIDT, F; FLEMING, H. P. Using lactic acid bacteria to improve the safety of minimally processed fruits and vegetables. Food Technology, v. 51, n. 9, p. 44-51, 1997.

CARLIN, F.; NGUYEN-THE, C.; da SILVA, A. A. Factors affecting the growth of Listeria monocytogenes on minimally processed fresh endive. Journal of Applied Bacteriology, v. 78, n. 6, p. 636-646, 1995.

CARNELOSSI, M. A. G. Fisiologia pós-colheita de folhas de couve (Brassica oleraceae cv. acephala) minimamente processadas. Viçosa, 2000. 79 p. Tese (Doutorado em Fisiologia Vegetal) Universidade Federal de Viçosa (UFV).

CASE, R. A; BRADLEY, R. L.; WILLIAMS, R. R. Chemical and physical methods. In: RICHARDSON, G. H. (Ed.) Standard methods for the examination of dairy products. $15 \mathrm{ed}$. Washington, D.C.: American Public Health Association, 1985. p. 327-404.

CATELLANI, P.; GIACCONE, V.; NOVELLI, E. Microbial flora of freshly-produced vegetables: A preliminary report. Veterinary Research Communications, v. 30, n. 4, p. 345-347, 2006.

DANTAS, M. I. S. Impacto da embalagem de couve (Brassica oleraceae cv. acephala) minimamente processada na intenção de compra do consumidor. Viçosa, MG, 2001. 77 p. Dissertação (Tecnologia de Alimentos) - Universidade Federal de Viçosa (UFV).

DEGNAN, A. J.; YOUSEF, A. E.; LUCHANSKY, J. B. Use of Pediococcus acidilactici to control Listeria monocytogenes in temperature-abused vacuum-packaged wieners. Journal of Food Protection, v. 55, n. 2, p. 98-103, 1992.

DHOKANE, V. S. et al. Radiation processing to ensure safety of minimally processed carrot (Daucus carota) and cucumber (Cucumis sativus): optimization of dose for the elimination of Salmonella Typhimurium and Listeria monocytogenes. Journal of Food Protection, v. 69, n. 2, p. 444-448, 2006.

FANTUZZI, E.; PUSCHMANN, R.; VANETTI, M. C. D. Microbiota contaminante em repolho minimamente processado. Ciência e Tecnologia de Alimentos, v. 24, n. 2, p. 207-211, 2004.

FARBER, J. M. et al. Changes in populations of Listeria monocytogenes inoculated on packaged fresh-cut vegetables. Journal of Food Protection, v. 61, n. 2, p. 192-195, 1998.

FARBER, J. M. Microbiological aspects of modified-atmosphere packaging technology - A review. Journal of Food Protection, V. 54, n. 1, p. $58-70,1991$.

FRANCIS, G. A.; O'BEIRNE, D. Effects of type, package atmosphere and storage temperature on growth and survival of Escherichia coli O157:H7 and Listeria monocytogenes. Journal of Industrial Microbiology and Biotechnology, v. 27, n. 2, p. 111-116, 2001.

GANDHI, M.; CHIKINDAS, M. L. Listeria: a foodborne pathogen that knows how to survive. International Journal of Food Microbiology, v. 113, n.1, p. 1-15, 2007.

HALL, P. A.; LEDENBACH, L.; FLOWERS, R. S. Acid-producing microorganisms. In: DOWNES, F. P.; ITO, K. A. Compendium of methods for the microbiological examination of foods. $4 \mathrm{ed}$. Washington: American Public Health Association (APHA), 2001. p. 201-207.

MANVELL, P. M.; ACKLAND, M. R. Rapid detection of microbial growth in vegetable salads at chill and abuse temperatures. Food Microbiology, v. 3, n. 1, p. 59-65, 1986.

MARTH, E. H. Extended shelf life refrigerated foods: microbiological quality and safety. Food Technology, v. 52, n. 2, p. 57-62, 1998.

NGUYEN-THE, C.; CARLIN, F. The microbiology of minimally processed fresh fruits and vegetables. Critical Reviews in Food Science and Nutrition, v. 34, n. 4, p. 371-401, 1994.

NORRUNG, B. Microbiological criteria for Listeria monocytogenes in foods under special consideration of risk assessment approaches. International Journal of Food Microbiology, v. 62, n. 3, p. 217-221, 2000

NORRUNG, B.; ANDERSEN, J. K.; SCHLUNDT, J. Incidence and control of Listeria monocytogenes in foods in Denmark. International Journal of Food Microbiology, v. 53, n. 3, p. 195-203, 1999.

ODUMERU, J. A. et al. Assessment of the microbiological quality of ready-to-use vegetables for health-care food services. Journal of Food Protection, v. 60, n. 8, p. 954-960, 1997.

OKTEM, A. B. et al. Prevalence of Listeria monocytogenes in some Turkish foodstuffs. Journal of Food Quality, v. 29, n. 1, p. 76-86, 2006.

PONCE, A. G. et al. Preliminary characterization of bacteriocinlike substances from lactic acid bacteria isolated from organic leafy vegetables. LWT - Food Science and Technology, 2007 (in press).

RODRÍGUEZ, A. M. C. et al. Growth modelling of Listeria monocytogenes in packaged fresh green asparagus. Food Microbiology, v. 17, n. 4, p. 421-427, 2000.

SANZ, S.; GIMÉNEZ, M.; OLARTE, C. Survival and growth of Listeria monocytogenes and enterohemorrhagic Escherichia coli O157:H7 in 
minimally processed artichokes. Journal of Food Protection, v. 66, n. 12, p. 2203-2209, 2003.

SCHILLINGER, U. et al. Efficacy of nisin in combination with protective cultures against Listeria monocytogenes Scott A in tofu. International Journal of Food Microbiology, v. 71, n. 2, p. 159-168, 2001.

SCHUENZEL, K. M.; HARRISON, M. A. Microbial antagonists of foodborne pathogens on fresh, minimally processed vegetables. Journal of Food Protection, v. 65, n. 12, p.1909-1915, 2002.

SINIGAGLIA, M. et al. Growth of Listeria monocytogenes in fresh-cut coconut as affected by storage conditions and inoculum size. Journal of Food Protection, v. 69, n. 4, p. 820-825, 2006.

SOOMRO, A. H.; MASUD, T.; ANWAAR, K. Role of lactic bacteria (LAB) in food preservation and human health - a review. Pakistan Journal of Nutrition, v. 1, n. 1, p. 20-24, 2002.

SORIANO, J. M. et al. Listeria species in raw and ready-to-eat foods from restaurants. Journal of Food Protection, v. 64, n. 4, p. 551-553, 2001.

SPELHAUG, S. R.; HARLANDER, S. K. Inhibition of foodborne bacterial pathogens by bacteriocins from Lactococcus lactis and Pediococcus pentosaceous. Journal of Food Protection, v. 52, p. 856-862, 1989.

SZABO, E. A.; SCURRAHAND, K. J.; BURROWS, J. M. Survey for psychrotrophic bacterial pathogens in minimally processed lettuce. Letters in Applied Microbiology, v. 30, n, 6, p. 456-460, 2000.
TELES, C. S. Avaliação física, química e sensorial de couve (Brassica oleraceae cv. acephala) minimamente processada, armazenada sob atmosfera modificada. Viçosa, MG, 2000. 115 p. Dissertação (Ciência e Tecnologia de Alimentos) - Universidade Federal de Viçosa (UFV).

THOMAS, C.; O'BEIRNE, D. Evaluation of the impact of short-term temperature abuse on the microbiology and shelf life of a model ready-to-use vegetable combination product. International Journal of Food Microbiology, v. 59, n. 1-2, p. 47-57, 2000.

VESCOVO, M. et al. Application of antimicrobial-producing lactic acid bacteria to control pathogens in ready-to-use vegetables. Journal of Applied Bacteriology, v. 81, n. 2, p. 113-119, 1996.

VESCOVO, M. et al. Inhibitory effect of selected lactic acid bacteria on microflora associated with ready-to-use vegetables. Letters in Applied Microbiology, v. 21, p. 121-125, 1995.

WATADA, A. E.; QI, L. Quality of fresh-cut produce. Postharvest Biology and Technology, v. 15, n. 3, p. 201-205, 1999.

WILEY, R. C. Introduction to minimally processed refrigerated fruits and vegetables. In: WILEY, R. C. (Ed.). Minimally processed refrigerated fruits \& vegetables. New York - London: Chapman \& Hall, 1994. p. 1-14.

WILSON, A. R.; SIGEE, D.; EPTON, H. A. S. Anti-bacterial activity of Lactobacillus plantarum strain SK1 against Listeria monocytogenes is due to lactic acid production. Journal of Applied Microbiology, v. 99, n. 6, p. 1516-1522, 2005. 